\title{
Infrared thermography applied to lower limb muscles in elite soccer players with functional ankle equinus and non-equinus condition
}

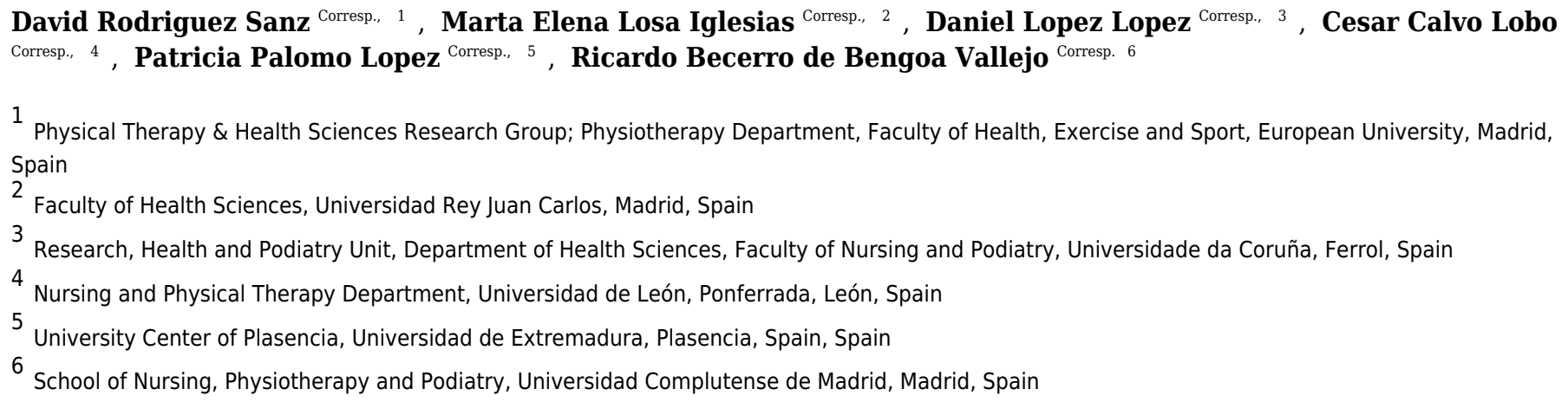

Corresponding Authors: David Rodriguez Sanz, Marta Elena Losa Iglesias, Daniel Lopez Lopez, Cesar Calvo Lobo, Patricia Palomo Lopez, Ricardo Becerro de Bengoa Vallejo

Email address: davidrodriguezsanz@gmail.com, marta.losa@urjc.es, daniellopez@udc.gal, cecalvo19@hotmail.com, patibiom@unex.es, ribebeva@ucm.es

Gastrocnemius-soleus equinus (GSE) is a foot-ankle complaint in which the extensibility of the gastrocnemius (G) and soleus muscles (triceps surae) and ankle are limited to a dorsiflexion beyond a neutral ankle position. The asymmetric forces of leg muscles and the associated asymmetric loading forces might promote major activation of the triceps surae, tibialis anterior, transverses abdominal and multifidus muscles. Here, we made infrared recordings of 21 sportsmen (elite professional soccer players) before activity and after 30 min of running. These recordings were used to assess temperature modifications on the gastrocnemius, tibialis anterior, and Achilles tendon in GSE and non-GSE participants. We identified significant temperature modifications among GSE and non-GSE participants for the tibialis anterior muscle (mean, minimum, and maximum temperature values). The cutaneous temperature increased as a direct consequence of muscle activity in GSE participants. IR imaging capture was reliable to muscle pattern activation for lower limb. Based on our findings, we propose that non-invasive IR evaluation is suitable for clinical evaluation of the status of these muscles. 
1 Infrared Thermography applied to lower limb muscles in elite soccer players with functional

2 ankle equinus and non-equinus condition.

3

4 Authors

5 David Rodriguez Sanz ${ }^{1}$, Marta Elena Losa Iglesias², Daniel Lopez Lopez ${ }^{3}$, Cesar Calvo Lobo ${ }^{4}$, Patricia

6 Palomo Lopez ${ }^{5}$, Ricardo Becerro de Bengoa Vallejo ${ }^{6}$

8 1.- Physical Therapy \& Health Sciences Research Group; Physiotherapy Department, Faculty of Health,

9 Exercise and Sport, European University, Madrid, Spain

2.-Faculty of Health Sciences, Universidad Rey Juan Carlos, Madrid, Spain

3.- Research, Health and Podiatry Unit, Department of Health Sciences, Faculty of Nursing and Podiatry,

Universidade da Coruña, Ferrol, Spain

4.- Nursing and Physical Therapy Department, Universidad de León, Ponferrada, León, Spain

5.- University Center of Plasencia, Universidad de Extremadura, Plasencia, Spain

6.- School of Nursing, Physiotherapy and Podiatry, Universidad Complutense de Madrid, Madrid, Spain

Corresponding author:

- David Rodriguez Sanz. Faculty of Health, Exercise and Sport, Department of Physical Therapy and Podiatry, Universidad Europea de Madrid, Villaviciosa de Odón, Madrid, Spain. Physical Therapy \& Health Sciences Research Group . (e-mail : davidrodriguezsanz@gmail.com)

- Marta Elena Losa Iglesias : Faculty of Health Sciences, Universidad Rey Juan Carlos, Madrid, Spain. ( e-mail : marta.losa@urjc.es)

- Patricia Palomo Lopez : University Center of Plasencia, Universidad de Extremadura, Plasencia, Spain. ( e-mail: patibiom@unex.es)

- Daniel Lopez Lopez : Research, Health and Podiatry Unit, Department of Health Sciences, Faculty of Nursing and Podiatry, Universidade da Coruña, Ferrol, Spain. ( e-mail: daniellopez@udc.gal)

- César Calvo Lobo. Universidad de Leon. Nursing and Physical Therapy department. (email: cecalvo19@hotmail.com).

- Ricardo Becerro de Bengoa Vallejo : School of Nursing, Physiotherapy and Podiatry, Universidad Complutense de Madrid, Madrid, Spain. ( e-mail : ribebeva@ucm.es) 


\section{ABSTRACT}

Gastrocnemius-soleus equinus (GSE) is a foot-ankle complaint in which the extensibility of the gastrocnemius ( $\mathrm{G}$ ) and soleus muscles (triceps surae) and ankle are limited dorsiflexion beyond a neutral ankle position ${ }^{1,2}$. The asymmetric forces of leg muscles and the associated asymmetric loading forces might promote major activation of the triceps surae, tibialis anterior, transversus abdominus and multifidus muscles hence modify temperature. Here, we made infrared recordings of 21 sportsmen (elite professional soccer players) before activity and after $30 \mathrm{~min}$ of running. These recordings were used to assess temperature modifications on the gastrocnemius, tibialis anterior, and Achilles tendon in GSE and non-GSE participants. We identified significant temperature modifications among GSE and non-GSE participants for the tibialis anterior muscle (mean, minimum, and maximum temperature values). The cutaneous temperature mean GSE increased more than non-GSE . IR imaging reliably captured temperature associated with muscle pattern activation for lower limb. Based on our findings, we propose that non-invasive IR evaluation is suitable for clinical evaluation of the status of these muscles.

\section{INTRODUCTION}

Gastrocnemius-soleus equinus (GSE) is a functional limitation of the ankle. GSE is defined as the inability of the ankle to dorsiflex beyond a neutral position with the knee extended (it remains $<0^{\circ}$ ) or with the knee flexed (it remains $<0^{\circ}$ ) (after excluding osseus restriction) ${ }^{1,2}$. Although GSE is clinically asymptomatic, it may cause an alteration in the triceps surae muscles, tibialis anterior muscle (TA), and Achilles tendon (AT). GSE is closely related to asymmetric loading patterns and muscular alteration for contraction ${ }^{3-6}$.

Asymmetric body loading is associated with GSE and may cause a higher activation of low-back and pelvic muscles (e.g., the quadratus lumborum) and lower limb muscles (e.g., the TA). GSE has been much studied using the mean of force pressure platform, Romberg-test analysis, and sway-area development approaches 7,8,9,10. The relationships between muscle contraction condition and posture have been investigated by electromyography ${ }^{11,12,13}$. GSE condition shows a relationship with gait and posture 9,10 . Also, several studies have investigated whether activation of skeletal muscles promotes heat transfer and thus increases cutaneous temperature $14,15,16,17$.

Orthostatic posture is typically assessed by the complex activation of anti-gravitational muscles (e.g., the triceps surae muscles). Modifications in cutaneous temperature are associated with gait and posture alterations, asymmetric loading forces, and an altered range of ankle or knee movement. High thermal infrared (IR) imaging can non-invasively identify cutaneous temperature variations ${ }^{14}$. 
Here we aimed to assess whether high-resolution thermal IR can detect cutaneous temperature variations in GSE and Non-GSE individuals and thus detect association between the extensibility to triceps-surae (with GSE and Non-GSE) and the role of TA in professional sportsmen. The aim of the study was to check thermal differences between GSE and Non GSE-group before running and after running exercise.

\section{METHODS}

In this case-control study, 21 healthy male participants (professional soccer players) (age $23 \pm$ 2.9 years, body mass index (applying Quetelet's equation follow BMI = weight $(\mathrm{kg}) / \mathrm{height}(\mathrm{m})^{2}$ ) $20.2 \pm 1.2$ ) were included. A consecutive sampling method was used to select participants. Eighteen subjects were right-footed, and three were left-footed, as defined by the self-report on the lower limb predominant used in sports activities. All participants successfully completed the study. The exclusion criteria were the presence of musculoskeletal injuries, low back and pelvic pain, sprains, tendon injuries in lower limbs, use of drugs in the week preceding the test, and scoliosis.

The principal study variable was temperature. An IR ThermaCam was used to register the maximum, minimum and mean temperature values of the TA, AT, and $G$ regions.

Ethical considerations - The Research and Ethics Committee of the University of A Coruña (A Coruña, Spain; record number: CE 06/2014) approved the study. All subjects provided informed consent before the beginning of the study. The ethical standards for human experimentation of the Declaration of Helsinki were respected. The Strengthening the Reporting of Observational Studies in Epidemiology (STROBE) guidelines were applied. The study size was derived as a convenience sample method.

IR imaging - The subjects were given a series of standardization rules before attending the experimental measurements ${ }^{14}$. Specifically, during the week prior to the trial, the participants were asked not to use drugs. Also, on the test day, vasomotor substances (e.g., caffeine) and heavy meals were not allowed.

Paper signals were attached to the lower limb with anatomical references (TA, G, and AT). All measurements were acquired in a laboratory with a temperature of $24.1 \pm 1 \mathrm{C}^{\circ}$, humidity of $45 \%$ $\pm 10 \%$ and no direct ventilation-flow towards participants or raters.

Clinical exploration and capture of IR-imaging - First, participants lay in a supine position on a gurney, and their GSE status was assessed with the knee extended and flexed. The range of ankle dorsiflexion movement was checked using a goniometer to evaluate the angle between the plantar line of the foot and the tibia axis. The rater maintained the subtalar joint in a neutral position and the angle in a dorsiflexion position [rather than midfoot-dorsiflexion (rocker bottom) 
110 or midfoot-equinus (pseudoequinus)]. The Silverskiold-test was used to check GSE from other 111 types of equines ${ }^{3,4}$. A $20^{\circ}$ movement with the knee flexed and $10^{\circ}$ movement with the knee 112 extended was considered a normal range of ankle dorsiflexion $3,5,6$. Equinus analysis was 113 carried out by the same Podiatry Doctor (R.B.B.V) to ensure the reliability of measurements.

114 The IR-imaging process (high resolutions thermograms) started with the participant standing up 115 in a relaxed position. We captured the TA, G, and AT regions in that order. Five IR-images 116 were taken for every muscle. Participants then ran for $30 \mathrm{~min}$ on a treadmill at a speed of 9 $117 \mathrm{~km} / \mathrm{h}$ and the IR-imaging repeated.

118 IR-imaging was performed using an FLIR/SC3000/QWIP Thermacan infrared thermal device with a 8-9 $\mu \mathrm{m}$ spectral range and 0.02-K temperature sensitivity (NETD at $30 \circ \mathrm{C}$ ). The 320 $\times 240 /$ FPA device presents a 20。-lens. The images were captured with a $1.1 \mathrm{mrad}$ spatialresolution. IR-imaging acquisition was carried out by the same clinician (DRS) using a tripod.

\section{DATA ANALYSIS}

123 IR-images and data were analyzed using rater (DRS) with the FLIR® software Termocan Researcher Professional V.2.9.This software provides to rater the minimum, maximum and mean thermal values for the selected muscles. This body selections-regions were bilaterally selected with landmark position and selected by the blinded clinical operator who ignored hypothesis of study and the experimental conditions. An IR-Imaging example is shown in Figure 1. 


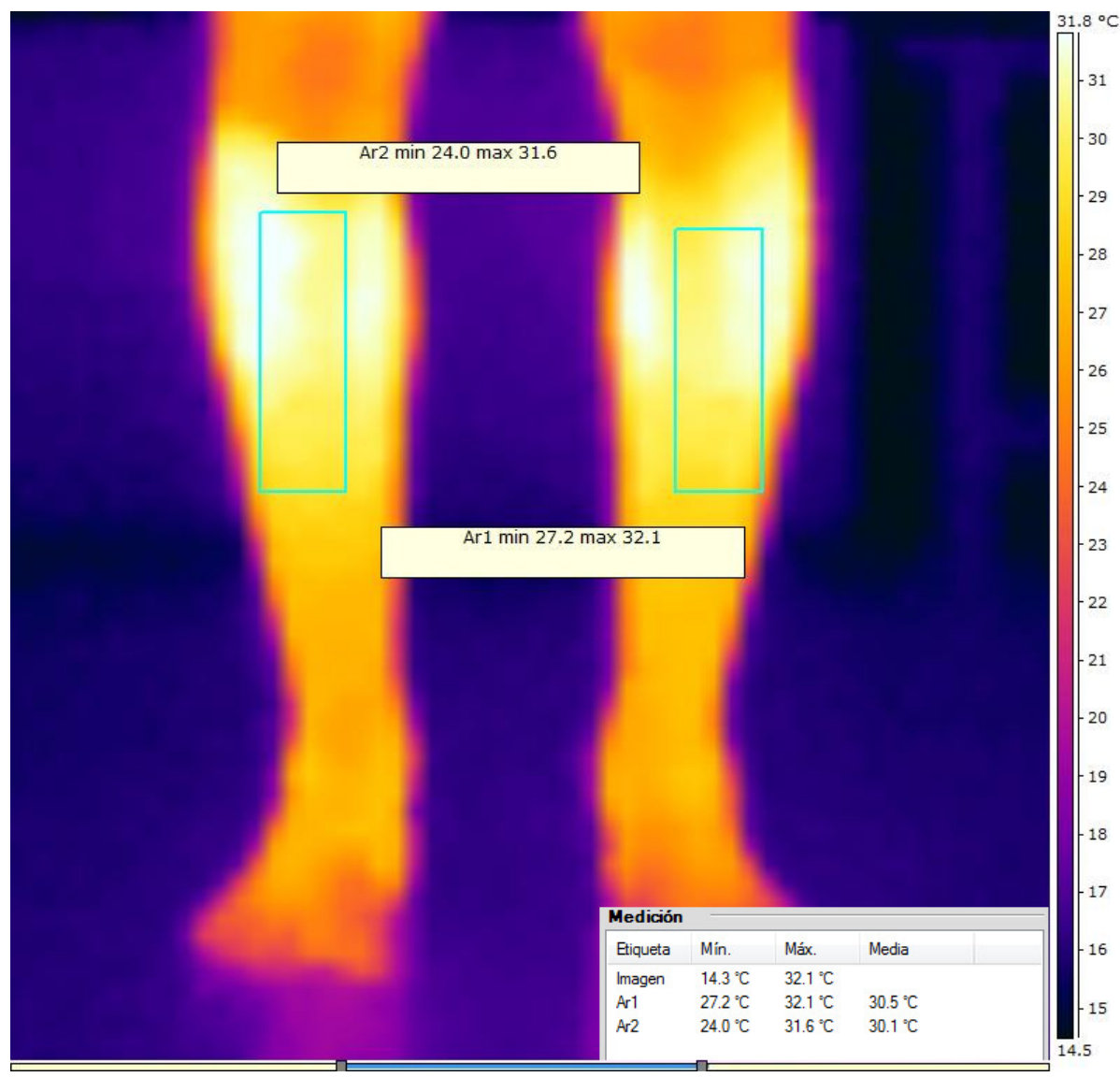

132 Statistical analyses were performed with SPSS (version 22.0 for Windows, IBM SPSS Statistics 133 for Windows, Armonk, NY, IBM Corp) with an a error of 0.05 (95\% confidence interval [Cl]), with 134 the desired power of $80 \%$ ( $\beta$ error of 0.2 ).

135 Shapiro-Wilks test was used to assess data normality. All data were normally distributed, and 136 parametric statistical tests were selected. The mean and standard deviation of the temperature data were obtained for the selected lower limb muscles (AT, TA, G).

138 Unpaired sample student's t test were performed to test for statistically significant differences in 139 height, weight, body mass index, and age between the two groups. A Paired Student's t-tests 140 were performed to determine differences between the groups (equinus vs. non-equinus), as well as between imaging sessions (before vs. after running).

\section{RESULTS}

144 We found no statistically significant differences between the equinus vs. non-equinus groups for participant height, weight, age or body mass index (Table 1). 
Table 1. Participant characteristics ( $n=10$ non-equinus and 11 equinus participants)

\begin{tabular}{|l|l|l|}
\hline & Equinus Group & Non- Equinus Group \\
\hline Age $($ years) & & \\
\hline Height $(\mathrm{cm})^{*}$ & $23.56 \pm 2.61(21-28)$ & $20 \pm 2.16(19-27)$ \\
\hline Weight $(\mathrm{kg})^{*}$ & $175.5 \pm 7.9$ & $173.1 \pm 5.2$ \\
\hline Body mass index & $75.2 \pm 3.9$ & $74.5 \pm 3.1$ \\
\hline
\end{tabular}

${ }^{*}$ No statistically significant difference between groups $(p \geq 0.05)$.

147 We found no significant differences in TA, G or AT temperatures between the GSE and non148 GSE participants before running (Table 2).

Table 2. Temperature values ( Degrees Celsius) for tibialis anterior, gastrocnemius-soleus and Achilles tendon for gastrosoleus equinus (GSE) and non-gastrosoleus equinus (Non-GSE) participants before exercise.

\begin{tabular}{|c|c|c|c|}
\hline Variable & Mean & SD & $P$ value \\
\hline \multicolumn{4}{|c|}{ Tibialis right anterior minimum temperature before exercise } \\
\hline \multirow{2}{*}{$\begin{array}{l}\text { GSE } \\
\text { Non GSE }\end{array}$} & 31.01 & \pm 1.3 & \multirow{2}{*}{$\begin{array}{l}, 342^{*} \\
, 331^{*}\end{array}$} \\
\hline & 30.86 & \pm 0.56 & \\
\hline \multicolumn{4}{|c|}{ Tibialis anterior right maximum temperature before exercise } \\
\hline GSE & 30.85 & \pm 1.32 & \multirow{2}{*}{$\begin{array}{l}, 397^{*} \\
, 401^{*}\end{array}$} \\
\hline Non GSE & 31.07 & $\pm 0,81$ & \\
\hline \multicolumn{4}{|c|}{ Tibialis anterior right mean temperature before exercise } \\
\hline GSE & 31.3 & \pm 1.3 & \multirow{2}{*}{$\begin{array}{l}, 430^{*} \\
, 435^{\star}\end{array}$} \\
\hline Non GSE & 31.09 & \pm 0.56 & \\
\hline \multicolumn{4}{|c|}{ Tibialis anterior left minimum temperature before exercise } \\
\hline GSE & 28.82 & \pm 2.47 & $1,14^{*}$ \\
\hline Non GSE & 29.74 & \pm 0.82 & $1,15^{*}$ \\
\hline
\end{tabular}




\begin{tabular}{|c|c|c|c|}
\hline \multirow{2}{*}{$\begin{array}{l}\text { GSE } \\
\text { Non GSE }\end{array}$} & 31.87 & \pm 1.35 & \multirow{2}{*}{$\begin{array}{l}.486^{*} \\
, 504^{*}\end{array}$} \\
\hline & 31.65 & $\pm 0,53$ & \\
\hline \multicolumn{4}{|c|}{ Tibialis anterior left mean temperature before exercise } \\
\hline \multirow{2}{*}{$\begin{array}{l}\text { GSE } \\
\text { Non GSE }\end{array}$} & 31.01 & \pm 1.3 & \multirow{2}{*}{$\begin{array}{l}, 354^{*} \\
, 366^{*}\end{array}$} \\
\hline & 31.86 & \pm 0.56 & \\
\hline \multicolumn{4}{|c|}{ Gastrocnemius left minimum temperature before exercise } \\
\hline GSE & 28.41 & \pm 1.57 & \multirow{2}{*}{$\begin{array}{l}, 449^{*} \\
, 441^{*}\end{array}$} \\
\hline Non GSE & 28.71 & \pm 1.39 & \\
\hline \multicolumn{4}{|c|}{ Gastrocnemius left maximum temperature before exercise } \\
\hline GSE & 30.85 & \pm 1.32 & \multirow{2}{*}{$\begin{array}{l}, 442^{*} \\
, 452^{*}\end{array}$} \\
\hline Non GSE & 31.07 & $\pm 0,81$ & \\
\hline \multicolumn{4}{|c|}{ Gastrocnemius left mean temperature before exercise } \\
\hline GSE & 29.92 & \pm 1.34 & \multirow{2}{*}{$\begin{array}{l}, 687^{*} \\
, 681^{*}\end{array}$} \\
\hline Non GSE & 30.12 & \pm 0.84 & \\
\hline \multicolumn{4}{|c|}{ Gastrocnemius right minimum temperature before exercise } \\
\hline GSE & 28.35 & \pm 2.0 & \multirow{2}{*}{$\begin{array}{l}1,065^{*} \\
1,1^{*}\end{array}$} \\
\hline Non GSE & 29.1 & \pm 0.94 & \\
\hline \multicolumn{4}{|c|}{ Gastrocnemius right maximum temperature before exercise } \\
\hline GSE & 31.1 & \pm 1.14 & \multirow{2}{*}{$\begin{array}{l}, 357^{*} \\
, 362^{*}\end{array}$} \\
\hline Non GSE & 31.91 & $\pm 0,86$ & \\
\hline \multicolumn{4}{|c|}{ Gastrocnemius right mean temperature before exercise } \\
\hline GSE & 29.89 & \pm 1.14 & \multirow{2}{*}{$\begin{array}{l}608^{*} \\
, 614^{*}\end{array}$} \\
\hline Non GSE & 30.17 & \pm 0.93 & \\
\hline \multicolumn{4}{|c|}{ Achilles tendon left minimum temperature before exercise } \\
\hline GSE & 22.52 & \pm 3.59 &, $581^{*}$ \\
\hline
\end{tabular}




\begin{tabular}{|c|c|c|c|}
\hline Non GSE & 23.22 & \pm 1.16 &, $605^{\star}$ \\
\hline \multicolumn{4}{|c|}{ Achilles tendon Left maximum temperature before exercise } \\
\hline \multirow{2}{*}{$\begin{array}{l}\text { GSE } \\
\text { Non GSE }\end{array}$} & 29.52 & \pm 1.58 & \multirow{2}{*}{$\begin{array}{l}819^{*} \\
, 815^{*}\end{array}$} \\
\hline & 28.93 & \pm 1.75 & \\
\hline \multicolumn{4}{|c|}{ Achilles tendon left mean temperature before exercise } \\
\hline GSE & 26.57 & \pm 1.92 & \multirow{2}{*}{$\begin{array}{l}393^{*} \\
, 399^{*}\end{array}$} \\
\hline Non GSE & 26.87 & \pm 1.47 & \\
\hline \multicolumn{4}{|c|}{ Achilles tendon right minimum temperature before exercise } \\
\hline GSE & 22.74 & \pm 2.34 & \multirow{2}{*}{$\begin{array}{l}\text {,364* } \\
, 367^{*}\end{array}$} \\
\hline Non GSE & 23.05 & \pm 1.26 & \\
\hline \multicolumn{4}{|c|}{ Achilles tendon right maximum temperature before exercise } \\
\hline GSE & 29.57 & \pm 1.88 & \multirow{2}{*}{$\begin{array}{l}, 062^{*} \\
, 064^{*}\end{array}$} \\
\hline Non GSE & 29.51 & \pm 1.13 & \\
\hline \multicolumn{4}{|c|}{ Achilles tendon right mean temperature before exercise } \\
\hline GSE & 26.29 & \pm 1.68 & \multirow{2}{*}{$\begin{array}{l}1,48^{*} \\
1,47^{*}\end{array}$} \\
\hline Non GSE & 27.46 & \pm 1.93 & \\
\hline
\end{tabular}

* No statistically significant difference between groups $(p \geq 0.05)$. † Statistically significant difference between groups $(P<0.05) . N=10$ non-equinus and $N=11$ equinus participants

152 However, after running, the TA temperature (minimum, maximum, and mean) was significantly 153 warmer in the GSE than the Non GSE participants $(P<.05)$. Also, the minimum $G$ temperatures 154 (both right and left) and left AT mean temperature were significantly warmer in the GSE than the 155 Non-GSE participants (Table 3).

Table 3. Temperature values (Degrees Celsius) for tibialis anterior, gastrocnemius-soleus and Achilles tendon for gastrosoleus equinus (GSE) and non-gastrosoleus equinus (Non-GSE) participants after exercise.

\begin{tabular}{|l|l|l|l|}
\hline Variable & Mean & SD & P value \\
\hline \multicolumn{2}{|l|}{ Tibialis anterior right minimum temperature after exercise } \\
\hline
\end{tabular}




\begin{tabular}{|c|c|c|c|}
\hline $\begin{array}{l}\text { Non GSE } \\
\text { GSE }\end{array}$ & $\begin{array}{l}27.1 \\
29.04\end{array}$ & \begin{tabular}{|l|} 
\pm 1.9 \\
\pm 0.76
\end{tabular} & $\begin{array}{l}.007 \dagger \\
\text {,008† }\end{array}$ \\
\hline \multicolumn{4}{|c|}{ Tibialis anterior right maximum temperature after exercise } \\
\hline \multirow{2}{*}{$\begin{array}{l}\text { Non GSE } \\
\text { GSE }\end{array}$} & 30.28 & \pm 1.53 & \multirow{2}{*}{$\begin{array}{l}.006 \dagger \\
, 006 \dagger\end{array}$} \\
\hline & 31.95 & $\pm 0,8$ & \\
\hline \multicolumn{4}{|c|}{ Tibialis anterior right mean temperature after exercise } \\
\hline \multirow{2}{*}{$\begin{array}{l}\text { Non GSE } \\
\text { GSE }\end{array}$} & 29.14 & \pm 1.88 & \multirow{2}{*}{$\begin{array}{l}.035 \dagger \\
.034 \dagger\end{array}$} \\
\hline & 30.63 & \pm 0.89 & \\
\hline \multicolumn{4}{|c|}{ Tibialis anterior left minimum temperature after exercise } \\
\hline \multirow{2}{*}{$\begin{array}{l}\text { Non GSE } \\
\text { GSE }\end{array}$} & 27.12 & \pm 1.63 & \multirow{2}{*}{$\begin{array}{l}, 001 \dagger \\
, 001 \dagger\end{array}$} \\
\hline & 29.42 & \pm 0.65 & \\
\hline \multicolumn{4}{|c|}{ Tibialis anterior left maximum temperature after exercise } \\
\hline \multirow{2}{*}{$\begin{array}{l}\text { Non GSE } \\
\text { GSE }\end{array}$} & 30.52 & \pm 1.19 & \multirow{2}{*}{$\begin{array}{l}, 038 \dagger \\
, 038 \dagger\end{array}$} \\
\hline & 31.72 & \pm 1.25 & \\
\hline \multicolumn{4}{|c|}{ Tibialis anterior left mean temperature after exercise } \\
\hline \multirow{2}{*}{$\begin{array}{l}\text { Non GSE } \\
\text { GSE }\end{array}$} & 29.36 & \pm 1.62 & \multirow{2}{*}{$\begin{array}{l}.029 \dagger \\
, 027 \dagger\end{array}$} \\
\hline & 30.77 & \pm 1.04 & \\
\hline \multicolumn{4}{|c|}{ Gastrocnemius left minimum temperature after exercise } \\
\hline \multirow{2}{*}{$\begin{array}{l}\text { Non GSE } \\
\text { GSE }\end{array}$} & 27.92 & \pm 1.65 & \multirow{2}{*}{$\begin{array}{l}.033 \dagger \\
, 031 \dagger\end{array}$} \\
\hline & 29.38 & \pm 1.16 & \\
\hline \multicolumn{4}{|c|}{ Gastrocnemius left maximum temperature after exercise } \\
\hline \multirow{2}{*}{$\begin{array}{l}\text { Non GSE } \\
\text { GSE }\end{array}$} & 30.31 & \pm 1.39 & \multirow{2}{*}{$\begin{array}{l}, 036 \dagger \\
, 035 \dagger\end{array}$} \\
\hline & 31.32 & \pm 1.22 & \\
\hline \multicolumn{4}{|c|}{ Gastrocnemius left mean temperature after exercise } \\
\hline Non GSE & 29.27 & \pm 1.53 &, $063^{*}$ \\
\hline
\end{tabular}




\begin{tabular}{|c|c|c|c|}
\hline GSE & 30.44 & \pm 1.12 &, $06^{*}$ \\
\hline \multicolumn{4}{|c|}{ Gastrocnemius right minimum temperature after exercise } \\
\hline Non GSE & 27.81 & \pm 1.67 & \multirow{2}{*}{$\begin{array}{l}, 025 \dagger \\
, 024 \dagger\end{array}$} \\
\hline GSE & 29.29 & \pm 0.97 & \\
\hline \multicolumn{4}{|c|}{ Gastrocnemius right maximum temperature after exercise } \\
\hline Non GSE & 30.5 & \pm 1.32 & \multirow{2}{*}{$\begin{array}{l}140^{\star} \\
, 135^{\star}\end{array}$} \\
\hline GSE & 31.3 & $\pm 0,98$ & \\
\hline \multicolumn{4}{|c|}{ Gastrocnemius right mean temperature after exercise } \\
\hline Non GSE & 29.20 & \pm 1.48 & \multirow{2}{*}{$\begin{array}{l}\text {,025† } \\
\text {,023† }\end{array}$} \\
\hline GSE & 30.55 & \pm 0.93 & \\
\hline \multicolumn{4}{|c|}{ Achilles tendon left minimum temperature after exercise } \\
\hline Non GSE & 24.04 & \pm 3.34 & \multirow{2}{*}{$\begin{array}{l}, 146^{*} \\
, 139^{*}\end{array}$} \\
\hline GSE & 25.75 & \pm 1.24 & \\
\hline \multicolumn{4}{|c|}{ Achilles tendon Left maximum temperature after exercise } \\
\hline \multirow{2}{*}{$\begin{array}{l}\text { Non GSE } \\
\text { GSE }\end{array}$} & 30.44 & \pm 2.02 & \multirow{2}{*}{$\begin{array}{l}, 278^{*} \\
, 267^{*}\end{array}$} \\
\hline & 31.23 & \pm 0.93 & \\
\hline \multicolumn{4}{|c|}{ Achilles tendon left mean temperature after exercise } \\
\hline \multirow{2}{*}{$\begin{array}{l}\text { Non GSE } \\
\text { GSE }\end{array}$} & 27.88 & \pm 2.13 & \multirow{2}{*}{$\begin{array}{l}\text {,020† } \\
\text {,019† }\end{array}$} \\
\hline & 29.87 & \pm 1.3 & \\
\hline \multicolumn{4}{|c|}{ Achilles tendon right minimum temperature after exercise } \\
\hline Non GSE & 24.41 & \pm 3.15 & \multirow{2}{*}{$\begin{array}{l}\text {,216* } \\
, 207^{*}\end{array}$} \\
\hline GSE & 25.85 & \pm 1.65 & \\
\hline \multicolumn{4}{|c|}{ Achilles tendon right maximum temperature after exercise } \\
\hline \multirow{2}{*}{$\begin{array}{l}\text { Non GSE } \\
\text { GSE }\end{array}$} & 30.27 & \pm 1.79 & \multirow{2}{*}{$\begin{array}{l}, 073^{*} \\
, 07^{*}\end{array}$} \\
\hline & 31.5 & \pm 1.02 & \\
\hline
\end{tabular}




\begin{tabular}{|l|l|l|l|}
\hline \multicolumn{4}{|l|}{ Achilles tendon right mean temperature after exercise } \\
\cline { 1 - 3 } $\begin{array}{l}\text { Non GSE } \\
\text { GSE }\end{array}$ & 27.91 & \pm 1.67 &, $006^{*}$ \\
\cline { 2 - 3 } & 29.85 & \pm 1.2 &, $005^{*}$ \\
\hline
\end{tabular}

${ }^{*}$ No statistically significant difference between groups $(p \geq 0.05)$. † Statistically significant difference between groups $(P<0.05) . N=10$ non-equinus and $N=11$ equinus participants

\section{DISCUSSION}

Here, we identified an increase in TA temperature after running in professional soccer professionals with GSE condition compared to those without GSE. The minimum $G$ temperatures (right and left lower limb) and mean AT (left lower limb) temperature were also higher in GSE than non-GSE participants.

Ankle torque was higher in GSE participants than non-GSE participants ${ }^{22}$. The TA requires stronger contraction in GSE condition and, therefore, might be affected early by fatigue, thus explaining our observed increase in TA temperature in GSE participants compared to non-GSE participants. While participants remain without running activity, we didn't found differences. The running exercise may serve a stimulus to increase temperature in muscles and consequently differences between groups.

Researchers have addressed the necessary degrees of ankle dorsiflexion and basal values. ${ }^{1,6}$ Biomechanically, the maximum ankle dorsiflexion during the stance-phase of a normal gait occurs before heel lift with the knee extended. ${ }^{1}$ The minimum ankle range of motion for normal gait is $10^{\circ}$ dorsiflexion and $20^{\circ}$ plantarflexion. ${ }^{1,2,6}$ The most deeply known range of movement values for ankle dorsiflexion in the reviewed literature for static evaluation that the minimum dorsiflexion movement for the ankle for normal gait is $10^{\circ}$ of motion. ${ }^{3},{ }^{18-23} \mathrm{GSE}$ produces a higher loading force to the foot and can lead to foot-ankle biomechanical pathologic (e.g., plantar fasciitis, pes planus, hallux abductus valgus, Achilles tendinosis, Charcot's midfoot collapse, and diabetic ulcerations). ${ }^{3}$ DiGiovanni et al. found GSE in patients with foot and ankle pain. ${ }^{1}$ However, GSE is also found in asymptomatic patients. ${ }^{24}$

Further studies will be needed to improve our knowledge of muscle condition and to establish the clinical relevance of the association between temperature and cutaneous muscle projection therapeutic assessment.

\section{CONCLUSIONS}

GSE participants had a higher TA muscle temperature after exercise that non-GSE participants. The GSE groups showed a higher TA skin temperature. Therefore, Infrared thermography, in the way it measures skin temperature, could serve as screening tool for preventing or therapeutic 
186

187

188

189

190

191

192

193

194

195

196

197

198

199

200

201

202

203

204

205

206

207

208

209

210

211

212

213

214

215

216

217

218

219

220

221

222

223

224

225

226

227

228

229

230

231

232

233

actions. Further research is needed to identify other factors associated with GSE condition, as well as to better understand the factors that contribute to different temperature pattern in the lower limbs.

\section{REFERENCES}

1.-DIGIOVANNI CW, KUO R, TEJWANI N, PRICE R, HANSEN ST Jr, CZIERNECKI J, SANGEORZAN BJ: Isolated gastrocnemius tightness. J Bone Joint Surg Am 84: 962, 2002.

2.-DOWNEY MS, BANKS AS: Gastrocnemius recession in the treatment of nonspastic ankle equinus: a retrospective study. J Am Podiatr Med Assoc 79: 159, 1989.

3.-LAMM BM, PALEY D, HERZENBERG JE: Gastrocnemius soleus recession: a simpler, more limited approach. JAPMA 95: 18, 2005.

4.-SILFVERSKIO"LD N: Reduction of the uncrossed two-jointmuscles of the leg to one-joint muscles in spastic conditions. Acta Chir Scand 56: 315, 1924.

5.-DOWNEY MS: “Ankle Equinus," in Comprehensive Textbookof Foot Surgery, 2nd Ed, Vol 1, ed by EDMcGlamry, AS Banks, MS Downey, p 687, Williams \&Wilkins, Baltimore, 1992.

6.-ROOT ML, ORIEN WP, WEED JH: Normal and Abnormal Function of the Foot, Spanish edition, Clinical Biomechanics Corp, Los Angeles, 1977.

7.-BLUSTEIN S, M, D'AMICO J C : Limb length discrepancy. Identification, clinical significance, and management J. Am. Podiatr. Med. Assoc. 75 200-6, 1985.

8.-MAHAR RK, KIRBY RL, McLEOD D A : Simulated leg-length discrepancy: its effect on mean center of pressure position and postural sway Arch. Phys. Med. Rehabil. 66 822-4, 1985.

9.-BHAVE A, PALEY D, HERZEMBERG J E : Improvement in gait parameters after lengthening for the treatment of limb-length discrepancy J. Bone Joint Surg. Am. 81 529-34, 1999.

10.-BLAKE RL, FERGUSON H: Limb length discrepancies J. Am. Podiatr. Med. Assoc. 82 338, 1992.

11.-VINK P, HUSON A : Lumbar back muscle activity during walking with a leg inequality Acta Morphol. Neerl.Scand. 25 261-71, 1987.

12.-GURNEY B, MERMIER C, ROBERGS R, GIBSON A and RIVERO D : Effects of limblength discrepancy on gait economy and lower-extremity muscle activity in older adults. J Bone Joint Surg. Am. 83-A 907-15, 2001.

13.-BALESTRA G, FRASINELLI S, KNAFLITZ M, MOLINARI F : Time-frequency analysis of surface myoelectric signals during athletic movement IEEE Eng. Med. Biol. Mag. 20 106-15, 2001. 
234

235

236

237

238

239

240

241

242

243

244

245

246

247

248

249

250

251

252

253

254

255

256

257

258

259

260

261

262

263

264

265

266

267

268

269

270

271

272
14.-MERLA A, IODICE P, TAMGHERLINI A, DE MICHELE G, DI ROMUALDO S, SAGGINI R and ROMANI G: Monitoring skin temperature in trained and untrained subjects throughout thermal video Conf. Proc. IEEE Eng. Med. Biol. Soc.2 1684-6, 2005.

15.-ZONTAK A, SIDEMAN S, VERBITSKY O, BEYAR R : Dynamic thermography: analysis of hand temperature during exercise Ann. Biomed. Eng. 26 988-93, 1998.

16.-KURT AMMER, DAMIANO FORMENTI. Editorial: Does the type of skin temperature distribution matter?.Therm. Internat. 26(2):51-54. 2016.

17.-FORMENTI D, LUDWIG N, ROSSI A, TRECOCI A, ALBERTI G, GARGANOB M, MERLAC A, AMMERD K, CAUMO A. Skin temperature evaluation by infrared thermography: Comparison of two image analysis methods during the nonsteady state induced by physical exercise. Infrared Physics and Technology. 81:32-40. 2017.

18.-MCGLAMRY ED, KITTING RW: Equinus foot: an analysis of the etiology, pathology and treatment techniques. JAPMA 63: 165, 1973.

19.-KNUTZEN KM, PRICE A: Lower extremity static and dynamic relationships with rearfoot motion in gait. JAPMA 84: 171, 1994.

20.-NUBER GW: Biomechanics of the foot and ankle during gait. Clin Sports Med 7: 1, 1988.

21.-LAVERY LA, ARMSTRONG DA, BOULTON AJM: Ankle equines deformity and its relationship to high plantar pressure in a large population with diabetes mellitus. JAPMA 92: 479, 2002.

22.-WROBEL JS, CONNOLLY JE, BEACH ML: Associations between static and functional measures of joint function in the foot and ankle. JAPMA 94: 535, 2004.

23.-WINTER DA: Kinematic and kinetic patterns in human gait: variability and compensating effects. Human Mov Sci 3: 51, 1984.

24.-BRODERSEN A, PEDERSEN B, REIMERS J: Foot deformities and relation to the length of leg muscles in Danish children aged 3-17 years. Ugeskr Laeger 155:3914,1993.

25.-ABATE M, DI CARLO L, DI ROMUALDO S, FERRETI A, ROMANI GL, MERLA A. :Postural adjustment in experimental leg length difference evaluated by means of thermal infrared imaging. Physiol. Meas. 31 (2010) 35-43 